\title{
Mitteilungen des BCD und der DGK
}

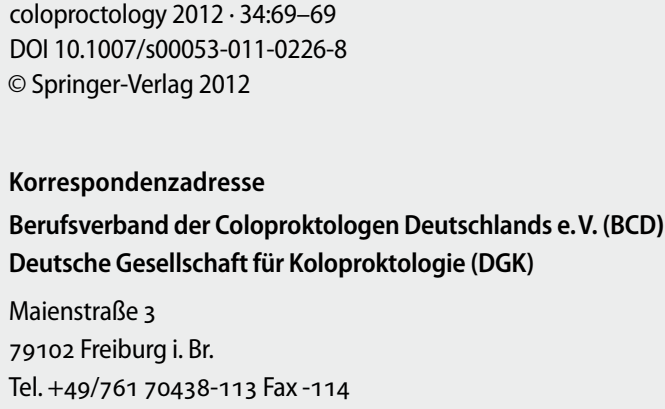

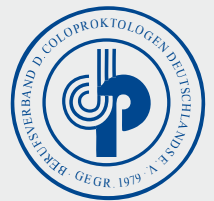

Berufsverband der Coloproktologen Deutschlands e.V. (BCD)

E-Mail:info@coloproktologen.de www.coloproktologen.de

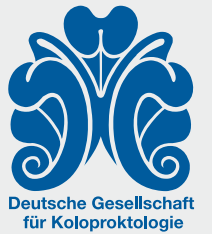

Deutsche Gesellschaft für Koloproktologie (DGK)

E-Mail: info@koloproktologie.org

www.koloproktologie.org

\section{Koloproktologischer Grundkurs}

\section{Berufsverbandes der Coloproktologen \\ Deutschlands e.V. (BCD)}

\section{in Zusammenarbeit mit der Deutschen \\ Gesellschaft für Koloproktologie e.V. (DGK)}

\section{Donnerstag, 15. März 2012, München}

\section{Begrüßung \\ B. Strittmatter,Freiburg \\ Vorsitzender des BCD}

\section{Vorsitz}

J. Meier zu Eissen, Hannover;

F. Raulf, Münster

$9.00-9.30 \mathrm{Uhr}$

Anatomie, Physiologie

F. Raulf, Münster

$9.30-10.00 \mathrm{Uhr}$

Anamnese und Untersuchung

M. Stoll, Hannover

$10.00-10.30 \mathrm{Uhr}$

Dermatologische

Erkrankungen

C. Breitkopf, Münster

$10.30-10.45 \mathrm{Uhr}$

Pause

10.45 - 11.15 Uhr

Differentialdiagnose „Hämorrhoiden"

J. Jongen, Kiel
11.15 - 11.45 Uhr

Hämorrhoiden

A. Furtwängler, Freiburg

$11.45-12.15 \mathrm{Uhr}$

Analfissur

B. Lenhard, Heidelberg

12.15 Uhr

Schriftlicher Test I

12.45 Uhr

Mittagspause

13.30 - 14.00 Uhr

AIN und Analkarzinom

C. Breitkopf, Münster

14.00 - 14.15 Uhr

Abszess und Fistel

C. Tamme, Hannover

14.15 - 14.30 Uhr

Inkontinenz

G. Osterholzer, München

14.30 - 15.00 Uhr Entleerungsstörung

A. Furtwängler, Freiburg
15.00 - 15.15 Uhr

Pause

$15.15-15.45 \mathrm{Uhr}$

Proktitis

M. Schmidt-Lauber, Oldenburg
15.45 - 16.15 Uhr

Rektum-Karzinom

G. Kolbert, Hannover

16.15 Uhr

Schriftlicher Test II 